\title{
Is self-expandable metallic stents superior to transanal decompression tubes for the treatment of malignant large-bowel obstruction: a meta-analysis
}

\author{
Fei Chen ${ }^{1}$, Qian Dong ${ }^{2}$, Fei Zhang ${ }^{2}$ \\ ${ }^{1}$ Department of General Surgery, Huadong Hospital, Affiliated to Fudan University, Shanghai, China; ${ }^{2}$ Department of General Surgery, Xinhua \\ Hospital, Affiliated to Shanghai Jiao Tong University, School of Medicine; Shanghai, China \\ Contributions: (I) Conception and design: All authors; (II) Administrative support: F Zhang, Q Dong; (III) Provision of study materials or patients: \\ None; (IV) Collection and assembly of data: F Chen; (V) Data analysis and interpretation: All authors; (VI) Manuscript writing: All authors; (VII) \\ Final approval of manuscript: All authors. \\ Correspondence to: Fei Zhang; Qian Dong. Department of General Surgery, Xinhua Hospital, Affiliated to Shanghai Jiao Tong University, School of \\ Medicine; No 1665 Kongjiang road, Shanghai, China. Email: zhangfei@xinhuamed.com.cn; dongqian@xinhuamed.com.cn.
}

\begin{abstract}
Background: Preoperative intestinal decompression, such as self-expandable metallic stents (SEMS) and transanal decompression tubes (TDT), has been widely used for patients with malignant large-bowel obstruction (MLBO). The aim of this study is to evaluate the clinical outcomes of SEMS for MLBO as a bridge to surgery compared to TDT.
\end{abstract}

Methods: We searched three databases, including PubMed, Embase, and Web of Science from inception until June 12, 2019. Risk ratio (RR) or weight mean difference (WMD) with 95\% CIs was used to calculate the data extracted from included studies.

Results: Five studies with 226 participants were included in this review. SEMS insertion showed significantly higher clinical success rate $(\mathrm{RR}=1.30,95 \% \mathrm{CI}: 1.06,1.60 ; \mathrm{P}=0.012)$ and technical success rate $(\mathrm{RR}=1.33,95 \% \mathrm{CI}: 1.07,1.65 ; \mathrm{P}=0.011)$, as well as higher rates of solid food intake $(\mathrm{RR}=27.15,95 \% \mathrm{CI}$ : 8.73, 84.45; $\mathrm{P}<0.001$ ) and temporal discharge ( $\mathrm{RR}=64.47,95 \% \mathrm{CI}: 9.10,456.57 ; \mathrm{P}<0.001)$, as compared with TDT insertion. Moreover, SEMS insertion significantly reduced the blood loss (WMD =-69.73 $\mathrm{mL}, 95 \%$ CI: -81.61, -57.85; $\mathrm{P}<0.001$ ), and prolonged the operative time (WMD =93.49 minutes, 95\% CI: 14.24, $172.75 ; \mathrm{P}=0.021$ ) in the treatment of MLBO. Duration of hospital stay, complication rate and mortality rate were comparable between the two treatments.

Discussion: Preoperative SEMS insertion offered better effects for MLBO, including higher success rate, and higher rates of solid food intake and temporary discharge, compared with TDT.

Keywords: Self-expandable metallic stents (SEMS); transanal decompression tubes (TDT); malignant largebowel obstruction (MLBO); meta-analysis

Submitted Dec 27, 2020. Accepted for publication Jun 02, 2021.

doi: 10.21037/apm-20-2600

View this article at: https://dx.doi.org/10.21037/apm-20-2600

\section{Introduction}

Colorectal cancer (CRC) ranks one of the most common cancers around the world (1), and $7-29 \%$ of CRC patients will suffer emergent malignant large-bowel obstruction (MLBO) at the time of diagnosis $(1,2)$. As a life-threatening oncologic emergency, MLBO has relatively higher morbidity and mortality rates, which ranges from 30-60\% and $7-22 \%$, respectively $(3,4)$. The high rates are caused by the poor general and intestinal condition of the patients, as well as the inadequate preoperative assessment and preparation (3-5). Two-stage surgery strategy is traditionally recommended in these patients, who underwent 
decompressive colostomy with or without tumor resection followed by delayed anastomosis (6). However, this method has been shown to reduce the quality of life (QoL) $(7,8)$, and $57 \%$ of patients would develop parastomal hernias and some other complications, such as foul smell and stool leakage $(9,10)$.

Recently, in order to improve the QoL and prognosis in patients with acute left-sided MLBO, many nonsurgical approaches have been developed, including placement of a self-expandable metallic stent (SEMS) (11-13) and transanal decompression tube (TDT) $(14,15)$. SEMS is considered as a preferable alternative intervention for decompression of MLBO. Previous meta-analysis (16-18) have shown that, SEMS insertion after surgery is more effective than emergency surgery alone, with lower rates of morbidity and stoma creation, as well as shorter duration of hospital stay (16-18). In 2020, SEMS has been recommended by the European Society of Gastrointestinal Endoscopy (ESGE) guidelines as bridge to surgery for MLBO (19). TDT insertion can also avoid the two-stage surgery for MLBO, however, its application is only limited to Eastern counties, including Japan and China (20,21).

SEMS insertion is currently regarded as an effective and safe option for MLBO as bridge to surgery in terms of shorter hospital stay, lower mortality and morbidity rates than emergency surgery, especially in Western countries. Whereas, TDT placement is used as a bridge to an elective surgery without stoma in limited areas, including Asia. Recently, several comparative studies have been reported regarding the clinical outcomes of SEMS and TDT for MLBO (22-26), however, the benefits and safety of the two techniques were not inconsistent among them. In order to address the issue, we performed this meta-analysis of eligible studies that compared the short-outcomes of these two decompression devices.

We present the following article in accordance with the PRISMA reporting checklist (available at https://dx.doi. org/10.21037/apm-20-2600).

\section{Methods}

\section{Search strategy}

This meta-analysis was performed according to the Preferred Reporting Items for Systematic Reviews and Meta-Analyses (PRISMA) guidelines (27). Relevant articles were identified using electronic databases (PubMed, Embase, and Web of Science) from their inception to
June 12, 2019. The search was not limited to language or publication status. The search terms we used were the followings: (metallic[All Fields] AND ("stents"[MeSH Terms] OR “stents"[All Fields] OR “stent”[All Fields])) AND (transanal[All Fields] AND ("drainage"[MeSH Terms] OR “drainage"[All Fields]) AND tube[All Fields]) AND (metallic[All Fields] AND ("stents"[MeSH Terms] OR “stents"[All Fields] OR “stent"[All Fields])). A manual literature search for potential studies using reference lists of included articles was also performed.

\section{Selection criteria}

Eligible studies must be: (I) randomized controlled trial (RCT), case-control study, cohort study, or comparative study; (II) adult patients who had been diagnosed with MLBO; (III) patients underwent SEMS or TDT; (IV) they must provide the following outcome measures: success rate, solid food intake, temporal discharge, surgery time, duration of hospital stay, and complications.

\section{Data extraction and quality assessment}

Two independent reviewers evaluated the eligibility of all identified publications from selected articles. The following information were extracted: study characteristics (study design, first author's name, year of publication, country), patient characteristics (mean age, gender, sample size in each group, clinical stage, tumor location), and the outcome data of comparison between intervention and control. In order to minimize data entry error, all data were entered by two independent reviewers and checked by a third review, and disagreement between them was resolved by discussion.

Study quality was evaluated by two independent reviewers using the modified Newcastle-Ottawa (NOS) scale (28). This method used 3 items to assess the methodological quality of a non-randomized trial (28). The total score was 9 points, and high score indicated high quality. A study was classified as high quality if the total score was more than 5 points (28).

\section{Statistical analysis}

Risk ratio (RR) with $95 \%$ confidence intervals (95\% CIs) was calculated as effect size for the meta-analysis of dichotomous data, weight mean difference (WMD) with $95 \%$ CIs for continuous data. Heterogeneity among the included studies was assessed using $\mathrm{Q}$ chi-square 


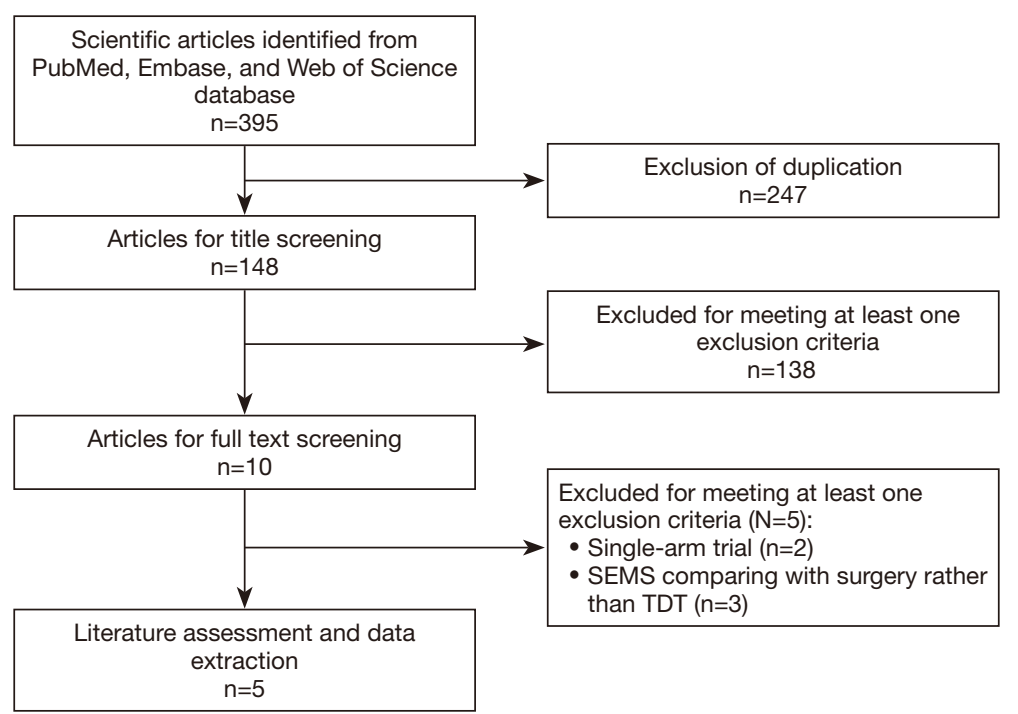

Figure 1 Eligibility of studies for inclusion in meta-analysis. SEMS, self-expandable metallic stents; TDT, transanal decompression tubes.

test, in which A $\mathrm{P}$ value less than 0.1 , or $\mathrm{I}^{2}$ greater than $50 \%$ represent significant heterogeneity (29). A randomeffects model (30) or a fixed-effects model (31) was used to pool the data according to the presence or absence of heterogeneity. For clinical heterogeneity, sensitivity analysis was performed to explore the potential sources of heterogeneity. The publication bias was not assessed since the number of included studies was less than 10 . A $\mathrm{P}$ value less than 0.05 was judged as statistically significant, except where otherwise specified.

\section{Results}

\section{Search results}

The initial screening retrieved 395 publications from the databases, of which 247 were removed because of duplicates. Then the review for title or abstract excluded 138 studies. In the next phase, 10 studies were screened for full-text information, in which 5 were excluded for a variety of reasons (singe-arm study design, non-comparison between SEMS and TDT). Then the remaining 5 studies (22-26) were identified for data extraction and meta-analysis. The detailed flow diagram is shown in Figure 1.

\section{Study characteristics}

Table 1 describes the detailed characteristics of the five included studies. Among these studies, four were performed in Japan (22,24-26) and one in China (23). The sample size in SEMS group ranged from 16 to 28, whereas that of TDT group ranged from 12 to 45 . All these studies were retrospective or prospective comparative studies, and no randomized controlled trials. Among the patients, 27.92\% of them were classified as pathological stage II, $41.12 \%$ as stage III, and $30.96 \%$ as stage IV. The NOS score of all the studies were greater than 5 points, which indicated that these studies were of high quality.

\section{Success rate (technical success, clinical success)}

All the articles provided the data of success rate (22-26). The overall success rate was $92.1 \%$ in SEMS group compared to $71.9 \%$ in TDT group. The pooled estimate showed that SEMS had better effects than TDT in terms of clinical success rate ( $\mathrm{RR}=1.30,95 \% \mathrm{CI}$ : 1.06, 1.60; $\mathrm{P}=0.012)$ and technical success rate $(\mathrm{RR}=1.33,95 \% \mathrm{CI}$ : $1.07,1.65 ; \mathrm{P}=0.011$ ) (Figure 2).

\section{Operative time}

Three studies presented the data of operative time (24-26). Significant heterogeneity $\left(\mathrm{I}^{2}=92.4 \%, \mathrm{P}<0.001\right)$ was observed across these studies that enrolled 76 patients in SEMS group and 90 patients in TDT group. SEMS significantly prolonged the operative time within the random-effects model (WMD =93.49 minutes, 95\% CI: 14.24, 172.75; $\mathrm{P}=0.021$ ) (Figure 3). 
Table 1 Baseline characteristics of patients in the trials included in the meta-analysis

\begin{tabular}{|c|c|c|c|c|c|c|c|}
\hline Study & Country & Treatment regimen & No. of patients & Male/female & Age (mean $\pm S D, y)$ & TNM stage (II/III/IV) & NOS score \\
\hline Kawachi J (22) & & TDT & 12 & $5 / 7$ & $74.1 \pm 10.5$ & $7 / 2 / 3$ & \\
\hline \multirow[t]{2}{*}{ Li CY (23) } & China & SEMS & 16 & $10 / 6$ & $73.3 \pm 8.5$ & NR & 6 \\
\hline & & TDT & 13 & $8 / 5$ & $72.6 \pm 4.7$ & NR & \\
\hline Matsuda A (24) & & TDT & 45 & $29 / 16$ & 70 [56-77] & $4 / 22 / 19$ & \\
\hline \multirow[t]{2}{*}{ Takeyama H (25) } & Japan & SEMS & 22 & $8 / 14$ & $71.3 \pm 10.3$ & $6 / 11 / 5$ & 6 \\
\hline & & TDT & 12 & $8 / 4$ & $68.5 \pm 10$ & $5 / 5 / 2$ & \\
\hline Kagami S (26) & Japan & SEMS & 26 & $17 / 9$ & 70 [50-85] & $11 / 6 / 9$ & 7 \\
\hline
\end{tabular}

SD, standard deviation; NOS, Newcastle-Ottawa; SEMS, self-expandable metallic stent; TDT, transanal decompression tube.

Study
ID

Figure 2 Forest plot showing the comparison between SEMS and TDT in clinical success rate and technical success rate. SEMS, selfexpandable metallic stents; TDT, transanal decompression tubes.

\section{Hospital stay}

All the articles provided the data of hospital stay (22-26), in which 111 patients participated in SEMS group and 115 in TDT group. The test for heterogeneity across the articles was found to be significant $\left(\mathrm{I}^{2}=96.6 \%, \mathrm{P}<0.001\right)$, thus a random-effects model was applied to summarize the data. Results demonstrated that, SEMS-treated patients had similar duration of hospital stay than TDT-treated patients $(W M D=1.58$ days, 95\% CI: $-15.90,19.06 ; \mathrm{P}=0.860)$ (Figure 4). Sensitivity analysis was conducted by excluding the trial with outlier (24) showed that, the summarized data $(\mathrm{WMD}=6.95$ days, 95\% CI: $-4.27,18.18 ; \mathrm{P}=0.225$ ) changed a lot but the heterogeneity was still present $\left(\mathrm{I}^{2}=79.6 \%, \mathrm{P}=0.002\right)$. 
Study

ID
$\%$

WMD $(95 \% \mathrm{Cl})$

Weight

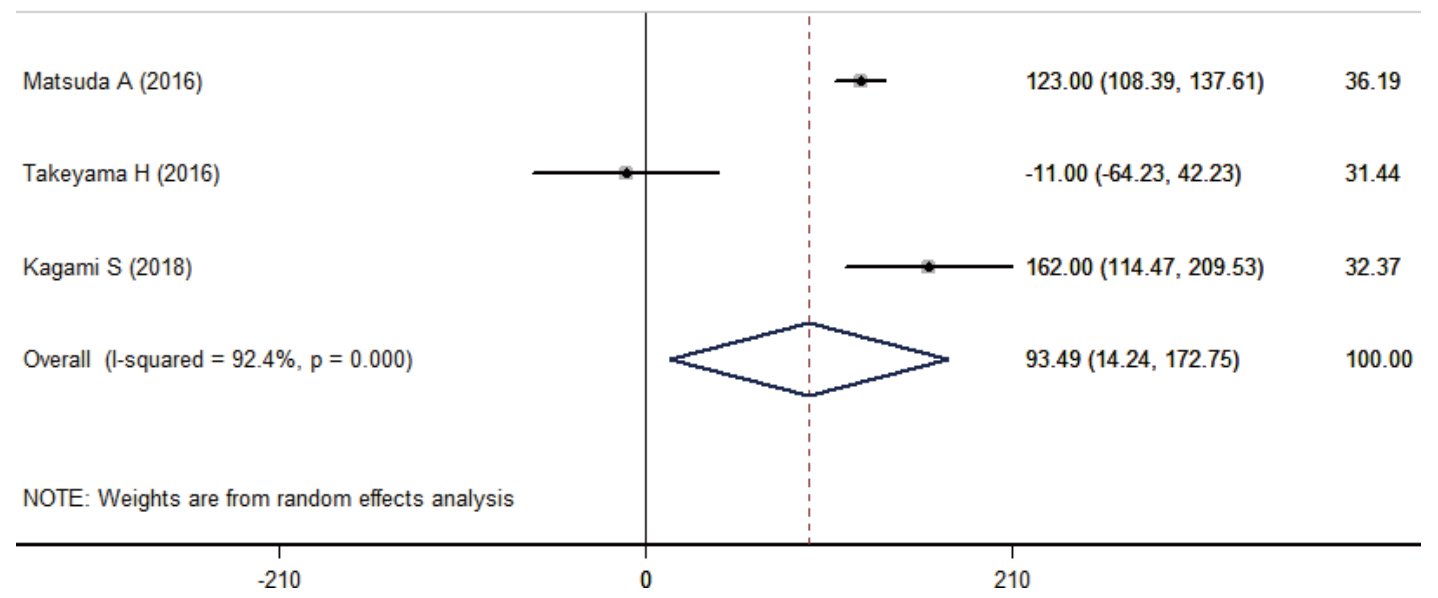

Figure 3 Forest plot showing the comparison between SEMS and TDT in operative time. SEMS, self-expandable metallic stents; TDT, transanal decompression tubes.

Study

ID
$\%$

WMD $(95 \% \mathrm{Cl}) \quad$ Weight

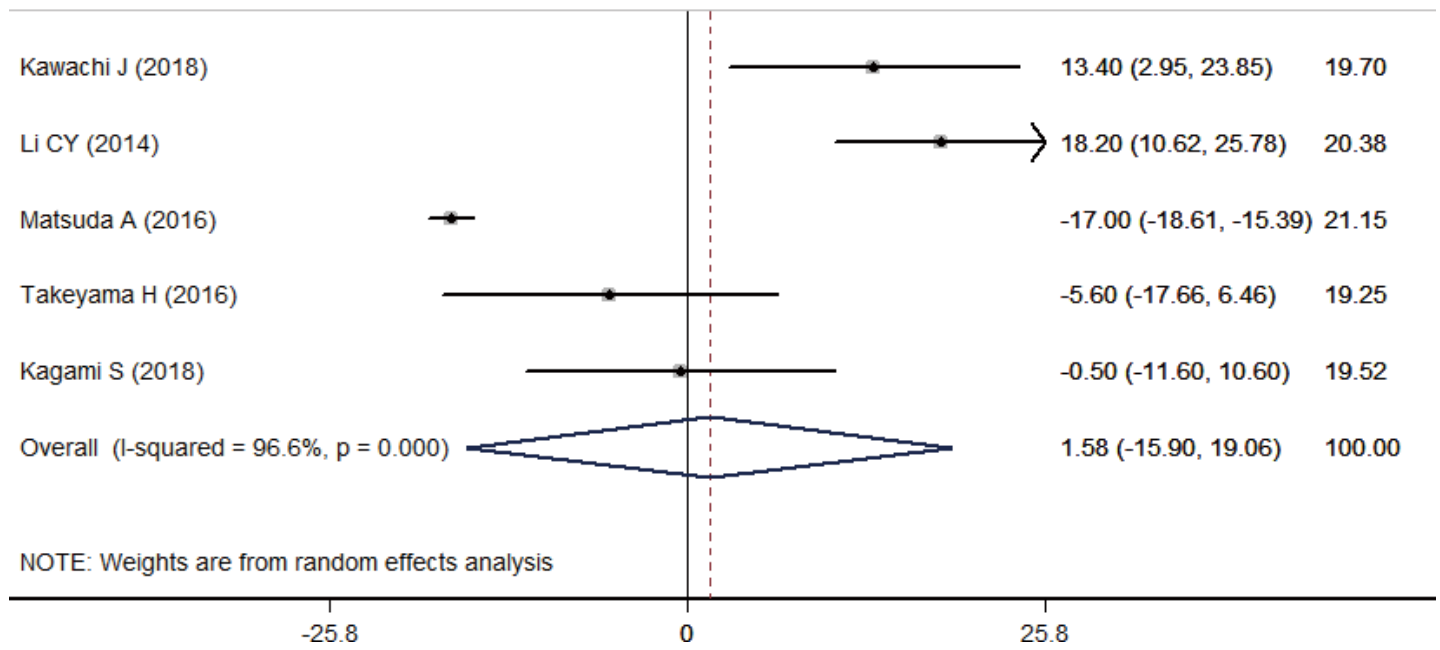

Figure 4 Forest plot showing the comparison between SEMS and TDT in hospital stay. SEMS, self-expandable metallic stents; TDT, transanal decompression tubes. 


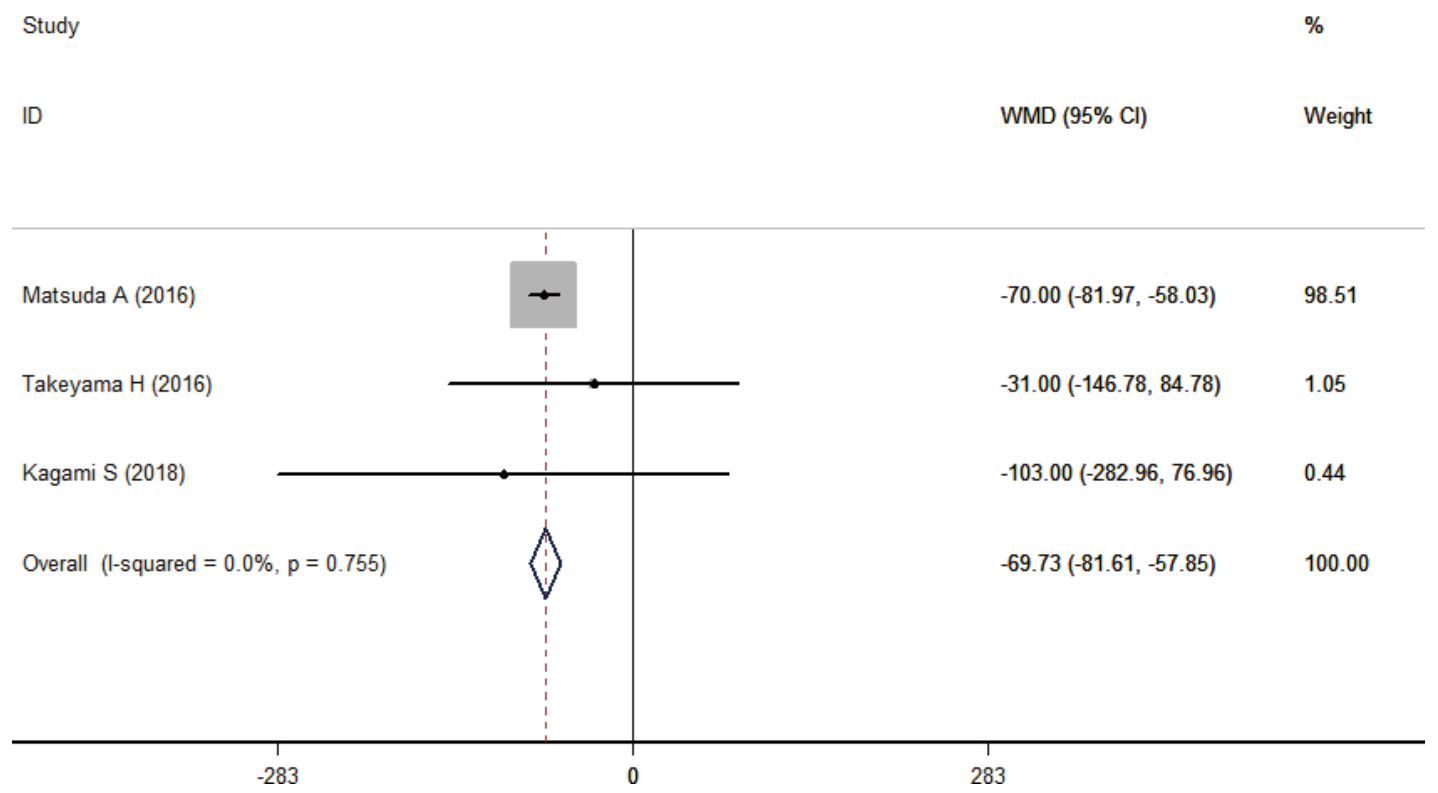

Figure 5 Forest plot showing the comparison between SEMS and TDT in blood loss. SEMS, self-expandable metallic stents; TDT, transanal decompression tubes.

\section{Blood loss}

The data of blood loss was reported in three studies (24-26). These studies involved 166 patients with 76 in SEMS group and 90 in TDT group. The heterogeneity across studies was not significant $\left(\mathrm{I}^{2}=0.0 \%, \mathrm{P}=0.755\right)$. Results using a fixedeffects model suggested that, the blood loss was significantly lower in SEMS group compared to that in TDT group $(\mathrm{WMD}=-69.73 \mathrm{~mL}, 95 \% \mathrm{CI}:-81.61,-57.85 ; \mathrm{P}<0.001)$ (Figure 5).

\section{Solid food intake and temporal discharge}

Three studies reported these data, however, only two of them $(24,26)$ provided available data. The rates of solid food intake and temporal discharge prior to surgery were $100 \%$ and $83.33 \%$ in SEMS group, and $2.56 \%$ and $0 \%$ in TDT group, respectively. Meta-analysis of these data revealed significantly better QoL in SEMS group than in TDT group, including solid food intake ( $\mathrm{RR}=27.15,95 \% \mathrm{CI}$ : 8.73, 84.45; $\mathrm{P}<0.001)$ and temporal discharge $(\mathrm{RR}=64.47$, 95\% CI: 9.10, 456.57; $\mathrm{P}<0.001)$. There was no significant heterogeneity across the articles.

\section{Mortality}

Two studies reported the data of mortality $(22,24)$. The mortality rate in SEMS and TDT group was $4.44 \%$ and $5.26 \%$, respectively. Pooled data indicated that the mortality rate in the two groups was comparable $(\mathrm{RR}=0.78,95 \% \mathrm{CI}$ : $0.12,4.69 ; \mathrm{P}=0.767)$.

\section{Complications}

All the included articles provided the complications (22-26). Pooled the results suggested that, there was no significant difference between the SEMS and TDT groups regarding the complications, including surgical site infection (RR $=0.72,95 \%$ CI: $0.23,2.28 ; \mathrm{P}=0.574$ ), anastomotic leakage ( $\mathrm{RR}=1.98,95 \% \mathrm{CI}: 0.40,9.78 ; \mathrm{P}=0.404)$, bowel obstruction ( $\mathrm{RR}=0.89,95 \%$ CI: $0.27,2.96 ; \mathrm{P}=0.842$ ), pneumonia (RR $=0.22,95 \%$ CI: $0.03,1.88 ; \mathrm{P}=0.167)$, stoma creation $(\mathrm{RR}$ $=2.12,95 \%$ CI: 0.36, 12.63; $\mathrm{P}=0.408)$, and perforation (RR $=0.18,95 \%$ CI: 0.02, 1.39; $\mathrm{P}=0.099$ ).

\section{Discussion}

The present meta-analysis included five studies and evaluated the clinical outcomes of SEMS for MLBO as a bridge to surgery compared to TDT. Data-analysis showed that, SEMS had significantly longer operative time, less blood loss, and higher success rate as compared with TDT. Patients' QoL as shown by solid food intake and 
temporal discharge was also better in SEMS group than in TDT group. However, the hospital stay and mortality rate were comparable between the two groups. Postoperative complications, including surgical site infection, anastomotic leakage, bowel obstruction, pneumonia, stoma creation and perforation, were also equivalent between the two treatment strategies. These results indicated the preoperative SEMS insertion was comparable with decompression with TDT regarding hospital stay, mortality and complications. However, SEMS provided better outcomes in terms of success rate and QoL compared with TDT.

In the present study, a significantly greater percentage of patients in SEMS group achieved success than in TDT group. The clinical and technical success rates of SEMS were $96.84 \%$ and $97.56 \%$, as compared with $75.23 \%$ and $70.97 \%$ for TDT, respectively. Our findings were consistent with the success rates of SEMS and TDT reported in the previous studies, which ranged from $83 \%$ to $100 \%$ for SEMS, and 60-90\% for TDT (20,23,32-34). Kagami et al. retrospectively collected data from 56 patients with malignant left-sided colon obstruction (26). They found that patients in SEMS group obtained significantly higher success rate than TDT (technical success rate: $94.7 \%$ vs. $58.3 \%$, clinical success rate: $89.4 \%$ vs. $41.7 \%$ ) (26). Previous study has reported that SEMS has a significantly higher clinical success rate than TDT, which might be due to its relatively larger internal diameter (35). Kawachi et al. (22) found that although the tumor size in TDT group was smaller than that in SEMS group, the clinical success rate for TDT was lower than SEMS (41.7\% vs. 89.4\%), which might be the result of the endoscopists' skill. The better effect of SEMS than TDT in success rate might be explained by the following reasons: (I) the guidewire is thinner for SEMS placement than for TDT, which makes it easier to pass through the tumor; (II) the hand-produced insertion force can be efficiently transmitted to the tip of SEMS device through the scope, maintaining a straight and rigid colonic axis (24). Therefore, SEMS placement could be relatively easily performed for both left-and right-sided MLBO.

In the present meta-analysis, SEMS increased the operative time and reduced blood loss in the treatment of MLBO when compared with TDT. Matsuda et al. (24) retrospectively reviewed 101 patients with MLBO (24), and showed that the surgery duration in SEMS group $\{258$ [162-313] minutes\}, was significantly longer than in TDT group $\{135$ [162-313] minutes\}; however, the blood loss was less in SEMS group than in TDT group, although the difference between them was not significant $(\mathrm{P}=0.360)$ (24). Similarly, Kagami et al. (26) also reported longer operative time and less blood less in SEMS group than in TDT group.

The most advantaged benefit of SEMS for MLBO than TDT was the maintenance of patients' preoperative QoL. SEMS-treated patients were able to initiate solid food intake and underwent preoperative temporary discharge when compared to TDT-treated patients. In the present study, SEMS had higher rates of solid food intake and temporal discharge than TDT. Matsuda et al. (24) reported that solid food intake after decompression and preoperative temporary discharge only occurred in SEMS group but not in TDT group (24). Kagami et al. (26) reported similar results in their retrospective study, which showed that all patients in SEMS group could initiate solid food intake and underwent preoperative temporary discharge from hospital (26).

Intestinal perforation was more frequently occurred in TDT group than in SEMS group, however, this difference was not significant. Previous studies revealed that the perforation rate of SEMS was generally comparable with that of TDT, with the corresponding values of ranging from $3 \%$ to $10 \%$, and $4 \%$ and $12 \%$, respectively $(23,36-38)$. However, in some other recent studies, they have suggested that the perforation rate of SEMS could be reduced to be $0 \%$ because of the technical improvement $(39,40)$. This was confirmed in the study of Matsuda et al. (24), in which no perforation occurred in SEMS group. The authors reported that this might be explained by the following possible reasons: (I) the guide wire was handled gently; (II) the SEMS was performed with low axial force in majority of patients (25 of 28, 89\%); (III) they chose a SEMS with appropriate length in order to avoid the contact with normal colonic mucosa (24).

There were several potential limitations. First, the sample size in some studies was relatively small. This would downgrade the overall quality of evidence about the effective comparison the two decompression advices for MLBO. Second, statistical analysis to assess publication bias was not assessed due to the limited number of included studies. Third, although no language restriction was imposed in the literature search, all the studies were published in English, which might result in language bias. Fourth, four of the five included studies were conducted in Japan, which potentially prevented the global application of these results. At last, due to the limited data, we did not perform meta-analysis to investigate survival-related outcomes (overall survival, progression free survival and 
local recurrence), as well as to explore whether some of the outcomes were influenced by potential factors (type of patients, tumor stage, and tumor location). Further studies focused on these issues are needed.

In conclusion, the present study suggested that, treatment with SEMS for MLBO had better effects than TDT, including higher success rate, less operative time and blood loss, as well as tolerance with higher rates of solid food intake and temporary discharge. Regarding the safety file, the two treatments were equivalent. However, the present meta-analysis is limited by small sample size and potential publication bias. Thus, more large-scale trials were needed to verify our findings.

\section{Acknowledgments}

The authors wish to acknowledge the native English speaker from CureEdit to improve the grammar and readability. Funding: None.

\section{Footnote}

Reporting Checklist: The authors have completed the PRISMA reporting checklist. Available at https://dx.doi. org/10.21037/apm-20-2600

Peer Review File: Available at https://dx.doi.org/10.21037/ apm-20-2600

Conflicts of Interest: All authors have completed the ICMJE uniform disclosure form (available at https://dx.doi. org/10.21037/apm-20-2600). The authors have no conflicts of interest to declare.

Ethical Statement: The authors are accountable for all aspects of the work in ensuring that questions related to the accuracy or integrity of any part of the work are appropriately investigated and resolved.

Open Access Statement: This is an Open Access article distributed in accordance with the Creative Commons Attribution-NonCommercial-NoDerivs 4.0 International License (CC BY-NC-ND 4.0), which permits the noncommercial replication and distribution of the article with the strict proviso that no changes or edits are made and the original work is properly cited (including links to both the formal publication through the relevant DOI and the license). See: https://creativecommons.org/licenses/by-nc-nd/4.0/.

\section{References}

1. Yeo HL, Lee SW. Colorectal emergencies: review and controversies in the management of large bowel obstruction. J Gastrointest Surg 2013;17:2007-12.

2. Dauphine CE, Tan P, Beart RW, Jr., et al. Placement of self-expanding metal stents for acute malignant largebowel obstruction: a collective review. Ann Surg Oncol 2002;9:574-9.

3. Deans GT, Krukowski ZH, Irwin ST. Malignant obstruction of the left colon. Br J Surg 1994;81:1270-6.

4. Barillari P, Aurello P, De Angelis R, et al. Management and survival of patients affected with obstructive colorectal cancer. Int Surg 1992;77:251-5.

5. Tekkis PP, Kinsman R, Thompson MR, et al. The Association of Coloproctology of Great Britain and Ireland study of large bowel obstruction caused by colorectal cancer. Ann Surg 2004;240:76-81.

6. Pavlidis TE, Marakis G, Ballas K, et al. Safety of bowel resection for colorectal surgical emergency in the elderly. Colorectal Dis 2006;8:657-62.

7. Näsvall P, Dahlstrand U, Lowenmark T, et al. Quality of life in patients with a permanent stoma after rectal cancer surgery. Qual Life Res 2017;26:55-64.

8. Fucini C, Gattai R, Urena C, et al. Quality of life among five-year survivors after treatment for very low rectal cancer with or without a permanent abdominal stoma. Ann Surg Oncol 2008;15:1099-106.

9. Feddern ML, Emmertsen KJ, Laurberg S. Life with a stoma after curative resection for rectal cancer: a population-based cross-sectional study. Colorectal Dis 2015;17:1011-7.

10. Mahjoubi B, Mirzaei R, Azizi R, et al. A cross-sectional survey of quality of life in colostomates: a report from Iran. Health Qual Life Outcomes 2012;10:136.

11. Baik SH, Kim NK, Cho HW, et al. Clinical outcomes of metallic stent insertion for obstructive colorectal cancer. Hepatogastroenterology 2006;53:183-7.

12. Li YD, Cheng YS, Li MH, et al. Management of acute malignant colorectal obstruction with a novel selfexpanding metallic stent as a bridge to surgery. Eur J Radiol 2010;73:566-71.

13. Wong KS, Cheong DM, Wong D. Treatment of acute malignant colorectal obstruction with self-expandable metallic stents. ANZ J Surg 2002;72:385-8.

14. Fischer A, Schrag HJ, Goos M, et al. Transanal endoscopic tube decompression of acute colonic obstruction: experience with 51 cases. Surg Endosc 2008;22:683-8. 
15. Horiuchi A, Maeyama H, Ochi Y, et al. Usefulness of Dennis Colorectal Tube in endoscopic decompression of acute, malignant colonic obstruction. Gastrointest Endosc 2001;54:229-32.

16. Cirocchi R, Farinella E, Trastulli S, et al. Safety and efficacy of endoscopic colonic stenting as a bridge to surgery in the management of intestinal obstruction due to left colon and rectal cancer: a systematic review and metaanalysis. Surg Oncol 2013;22:14-21.

17. Huang X, Lv B, Zhang S, et al. Preoperative colonic stents versus emergency surgery for acute left-sided malignant colonic obstruction: a meta-analysis. J Gastrointest Surg 2014;18:584-91.

18. Tan CJ, Dasari BV, Gardiner K. Systematic review and meta-analysis of randomized clinical trials of selfexpanding metallic stents as a bridge to surgery versus emergency surgery for malignant left-sided large bowel obstruction. Br J Surg 2012;99:469-76.

19. van Hooft JE, Veld JV, Arnold D, et al. Self-expandable metal stents for obstructing colonic and extracolonic cancer: European Society of Gastrointestinal Endoscopy (ESGE) Guideline - Update 2020. Endoscopy 2020;52:389-407.

20. Xu M, Zhong Y, Yao L, et al. Endoscopic decompression using a transanal drainage tube for acute obstruction of the rectum and left colon as a bridge to curative surgery. Colorectal Dis 2009;11:405-9.

21. Yamada T, Shimura T, Sakamoto E, et al. Preoperative drainage using a transanal tube enables elective laparoscopic colectomy for obstructive distal colorectal cancer. Endoscopy 2013;45:265-71.

22. Kawachi J, Kashiwagi H, Shimoyama R, et al. Comparison of efficacies of the self-expandable metallic stent versus transanal drainage tube and emergency surgery for malignant left-sided colon obstruction. Asian J Surg 2018;41:498-505.

23. Li CY, Guo SB, Wang NF. Decompression of acute left-sided malignant colorectal obstruction: comparing transanal drainage tube with metallic stent. J Clin Gastroenterol 2014;48:e37-42.

24. Matsuda A, Miyashita M, Matsumoto S, et al. Comparison between metallic stent and transanal decompression tube for malignant large-bowel obstruction. J Surg Res 2016;205:474-81.

25. Takeyama H, Kitani K, Wakasa T, et al. Self-expanding metallic stent improves histopathologic edema compared with transanal drainage tube for malignant colorectal obstruction. Dig Endosc 2016;28:456-64.
26. Kagami S, Funahashi K, Ushigome M, et al. Comparative study between colonic metallic stent and anal tube decompression for Japanese patients with left-sided malignant large bowel obstruction. World J Surg Oncol 2018;16:210.

27. Moher D, Liberati A, Tetzlaff J, et al. Preferred reporting items for systematic reviews and meta-analyses: the PRISMA statement. Bmj 2009;339:b2535.

28. Wells G, Shea B, O'connell D, et al. The NewcastleOttawa Scale (NOS) for assessing the quality of nonrandomized studies in meta-analyses. 3rd Symposium on Systematic Reviews: Beyond the Basics. 2000:3-5.

29. Higgins JP, Thompson SG, Deeks JJ, et al. Measuring inconsistency in meta-analyses. Bmj 2003;327:557-60.

30. DerSimonian R, Laird N. Meta-analysis in clinical trials. Control Clin Trials 1986;7:177-88.

31. Mantel N, Haenszel W. Statistical aspects of the analysis of data from retrospective studies of disease. J Natl Cancer Inst 1959;22:719-48.

32. Horiuchi A, Nakayama Y, Tanaka N, et al. Acute colorectal obstruction treated by means of transanal drainage tube: effectiveness before surgery and stenting. Am J Gastroenterol 2005;100:2765-70.

33. Gianotti L, Tamini N, Nespoli L, et al. A prospective evaluation of short-term and long-term results from colonic stenting for palliation or as a bridge to elective operation versus immediate surgery for large-bowel obstruction. Surg Endosc 2013;27:832-42.

34. Gorissen KJ, Tuynman JB, Fryer E, et al. Local recurrence after stenting for obstructing left-sided colonic cancer. Br J Surg 2013;100:1805-9.

35. Moroi R, Endo K, Ichikawa R, et al. The Effectiveness of Self-Expandable Metallic Stent Insertion in Treating Right-Sided Colonic Obstruction: A Comparison between SEMS and Decompression Tube Placement and an Investigation of the Safety and Difficulties of SEMS Insertion in Right Colons. Gastroenterol Res Pract 2014;2014:372918.

36. Shigeta K, Baba H, Yamafuji K, et al. Outcomes for patients with obstructing colorectal cancers treated with one-stage surgery using transanal drainage tubes. J Gastrointest Surg 2014;18:1507-13.

37. Sebastian S, Johnston S, Geoghegan T, et al. Pooled analysis of the efficacy and safety of self-expanding metal stenting in malignant colorectal obstruction. Am J Gastroenterol 2004;99:2051-7.

38. Small AJ, Coelho-Prabhu N, Baron TH. Endoscopic placement of self-expandable metal stents for malignant 
colonic obstruction: long-term outcomes and complication factors. Gastrointest Endosc 2010;71:560-72.

39. Tominaga K, Maetani I, Sato K, et al. Favorable long-term clinical outcome of uncovered D-weave stent placement as definitive palliative treatment for malignant colorectal

Cite this article as: Chen F, Dong Q, Zhang F. Is selfexpandable metallic stents superior to transanal decompression tubes for the treatment of malignant large-bowel obstruction: a meta-analysis. Ann Palliat Med 2021;10(7):7378-7387. doi: 10.21037/apm-20-2600 obstruction. Dis Colon Rectum 2012;55:983-9.

40. Yoshida S, Watabe H, Isayama H, et al. Feasibility of a new self-expandable metallic stent for patients with malignant colorectal obstruction. Dig Endosc 2013;25:160-6. 